\title{
COVID-I9 Pandemic: Disease Management and Current Therapeutics
}

\author{
Ipsita Chanda', Archana Pan' ${ }^{2}$, Pranavathiyani $\mathrm{G}^{3}$ \\ ${ }^{1}$ Department of Zoology, S.A. Jaipuria College, Kolkata, West Bengal, India. \\ ${ }^{2,3}$ Centre for Bioinformatics, Pondicherry University, Pondicherry, India. \\ DOI: https://doi.org/10.24321/0019.5138.202037
}

I $\quad \begin{array}{lll}\mathbf{N} & \mathbf{F} & \mathbf{O}\end{array}$

\section{Corresponding Author:}

Ipsita Chanda, Department of Zoology, S.A. Jaipuria College, Kolkata-700005, West Bengal,

India

E-mail Id:

icsajc@gmail.com

Orcid Id:

https://orcid.org/0000-0002-0795-294X

How to cite this article:

Chanda I, Pan A, Pranavathiyani G. COVID-19 Pandemic: Disease Management and Current Therapeutics. J Commun Dis 2020; 52(4): 29-34.

Date of Submission: 2020-06-20

Date of Acceptance: 2020-12-17

\section{$\begin{array}{llllllll}\mathbf{A} & \mathbf{B} & \mathbf{S} & \mathbf{T} & \mathbf{R} & \mathbf{A} & \mathbf{C} & \mathbf{T}\end{array}$}

The highly contagious disease COVID-19, caused by SARS-CoV-2, has emerged as a global pandemic. The high rate of contact transmission of this virus is the major cause of concern nowadays. Owing to the absence of any effective drugs/vaccines against COVID-19, many countries adopted 'lockdown' to minimize transmission of virus. The other means that was applied during lockdown, to mitigate the growth of infection is the 'test, trace, track and isolate'. However, different countries responded differently to these control measures with different outcome in the growth of infection. For now, several countries have started 'unlock', to handle the severe economic stress, created in response to lockdown. Again, lifting lockdown is another global threat, having the chance of second wave of infection. In such situation, the major challenge is to prevent the spread of infection, amid resumption of work. The present review is aimed to outline the prospect and future direction of disease management and current therapeutics against COVID-19.

Keywords: COVID-19, Lockdown, Test, Transmission of Virus, Drug

\section{Introduction}

The infectious disease COVID-19 (Corona Virus Disease-19) is caused by SARS-CoV-2 (Severe Acute Respiratory Syndrome Corona Virus-2), a novel coronavirus, and the etiological agent of ongoing global pandemic. SARS-CoV-2 is a beta subtype coronavirus in Coronaviridae family, having positive-sense single stranded RNA genome of large size (27-32 kb). ${ }^{1}$ The genome of this virus encodes a number of structural proteins like Spike (S), Envelope (E), Membrane $(\mathrm{M})$, Nucleocapsid (N), and non-structural proteins (nsp1 to nsp16). ${ }^{2}$ The disease was started at Wuhan city, Hubei province in central China during December, 2019 and spread to other countries of the world since early January, 2020, via infected persons, travelled from Wuhan. ${ }^{3}$ The average basic Reproduction Rate $\left(R_{0}\right)$ for COVID-19 was estimated to 3.28 , remarkably higher than $R_{0} 1.4$ to 1.7 , observed for Influenza. ${ }^{4}$ The virus is generally transmitted by the respiratory droplets ( $>5-10 \mu \mathrm{m})$, produced by coughs and sneezes of infected persons, among the persons in close contact (within $1 \mathrm{~m}$ ) or by faecal-oral route. ${ }^{5}$ Transmission may also occur by indirect contact through fomites in the immediate environment around infected persons, where it survives for hours. ${ }^{6}$ The most likely routes of virus into the host body are the cells, which express receptor protein, ACE2 and TMPRSS2 protease, activating SARS-CoV-2 to enter into the host cell. ${ }^{7}$ The mucus-producing goblet cells and ciliated cells in the inner lining of the nose, cells in the cornea of the eye, and in the lining of intestine have higher level of both these COVID-19 proteins. ${ }^{8}$ COVID-19 infection, usually affects lungs and airways with symptoms, flu-like fever, cough, sore-throat, and in worst case, exhibits severe acute respiratory syndrome that can lead to death. ${ }^{9}$ 
The infection spreads among individuals, range from the new born to elderly and from the persons with chronic disease (asthma, heart disease, diabetes, kidney disease, cancer) to healthy persons. ${ }^{9,10,11}$ SARS-CoV-2 is less fatal, with potentially higher rate of transmission. ${ }^{4}$ The people may carry transmissible virus, although they remain asymptomatic, and transmit the virus in presymptomatic stage as well. ${ }^{12}$ There are no approved drugs or vaccines for the effective treatment and protection against COVID-19. ${ }^{9}$ Hence, the disease management is the vital stand for prevention and control of the infection. Many countries with escalated growth of infection and death declared lockdown as a primary measure, to employ social distancing to minimize the spread of virus. ${ }^{13}$ This current article is the systematic review on the measures of disease management, and its prospect and future direction against COVID-19 pandemic. The review is made based on the published research articles and reports available on internet (PubMed and Google) until June 15, 2020.

\section{Epidemiology}

As on June 15, 2020, 11:29 GMT, a total number of confirmed cases reported worldwide was $8,018,838$, with approximately $5.34 \%$ rate of mortality $(436,138)$. USA had the highest number of confirmed cases $(1,839,054)$. The following countries in this respect were Brazil $(867,882)$, Russia $(537,210)$, India $(333,255)$, UK $(2,96,857)$ and others (Worldometer, real time data). ${ }^{14} \mathrm{~A}$ graph representing the number of new cases and deaths, every fortnight, since outbreak, illustrates that the countries like USA, UK, Spain, Germany, France, Italy and Canada, which were in the list of most severely infected countries from the beginning, have managed to decrease the number of new infections and deaths from the point of maximum upsurge. On the other hands, the same has been accelerating steadily in Brazil, India, Peru, Iran, Chile and Mexico (Figure 1).

\section{Disease Management and its Prospect}

Since the outbreak, many countries adopted the measures of lockdown and social distancing, to slow down the spread of COVID-19 virus by contact transmission, in a susceptible population. Lockdown, also offered time to trace/ track the infected persons to isolate/ quarantine them. ${ }^{15} \mathrm{WHO}$ recommended for hand hygiene, respiratory etiquette, environmental cleaning and disinfection to prevent person to person contamination. ${ }^{5}$ China, the country of largest population controlled the spread of disease by imposing stringent lockdown at Wuhan city, the epicentre for COVID-19 outbreak, and disrupting the communication of the city with other parts of China, in an ambitious and aggressive manner. The strong interventional policy helped China to shorten the duration of epidemic and reduce the number of new cases. ${ }^{16} \mathrm{~A}$ study with laboratory-confirmed cases of COVID-19 in Wuhan, China, (since December 8 , 2019 to March 8, 2020) illustrated the decrease of effective reproductive number $\left(R_{0}\right)$ below 1 (after February, 2020) from 3 (before January 26, 2020), owing to strict interventions like cordons sanitaire, traffic restriction, social distancing, home quarantine and centralized quarantine. ${ }^{17}$ India, the second largest population of the world, implemented 'tough and timely' lockdown, observing the intensity of infection and death of the pandemic in Indian scenario. ${ }^{18}$ This resulted in dropping down the rate of infection by $61 \%$, one week after lockdown in India. ${ }^{19}$ The timings of intervention were found effective, and strongly connected to the success of rapid reduction of infection and declining of effective reproduction number. ${ }^{20}$ The countries like Italy, USA, Spain, Germany, UK and France, in spite of their advanced and equipped healthcare system, failed to control the rate of infection and mortality initially, due to late and relaxed execution of lockdown. In comparison, the countries like Belgium, Austria, New Zealand, Hungary, Poland and

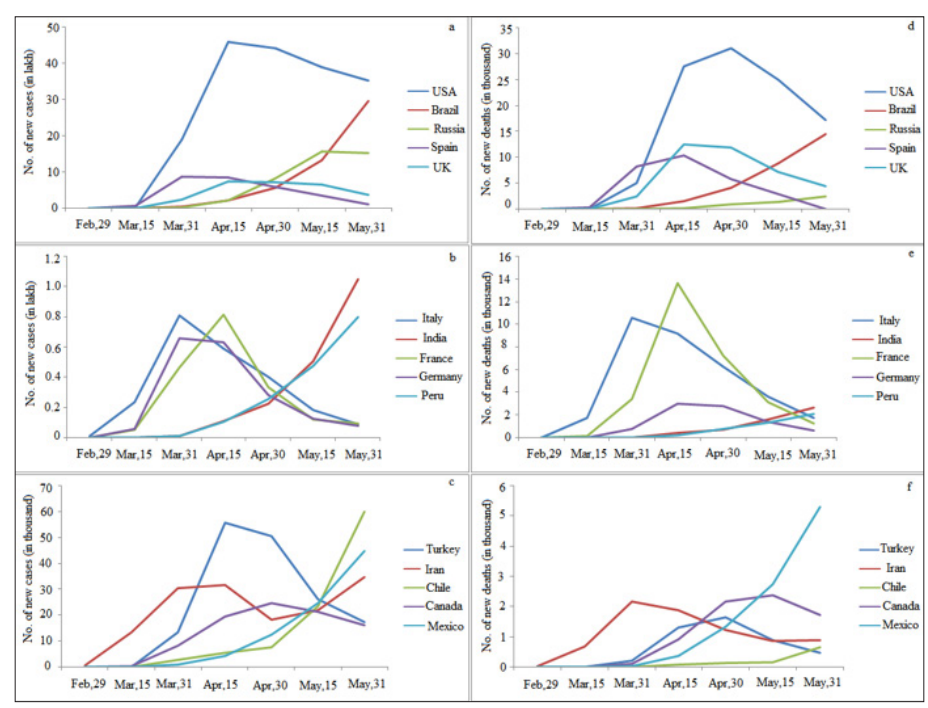

Figure I.The emerging trend of new cases $(a, b, c)$ and deaths $(d, e, f)$ in 15 top worst-hit countries in the world 
Malaysia that applied early lockdown, were fared good in this regard. ${ }^{19}$ Sweden did not impose strict lockdown and suffered initially from higher death rate (371/million) than its neighbouring countries like Norway (43), Demark (95) and Finland (54), who adopted stringent containment measures (as of May 19, 2020). ${ }^{21}$

Another measure of disease management that was initiated during lockdown is 'test, trace, track and isolation', to prevent the spread of virus, gradually. ${ }^{15}$ The mass testing approach traces and isolates asymptomatic and minimum/ moderately symptomatic COVID-19 patients, tracks the persons exposed to the infected ones, and quarantined them to prevent the transmission of virus. ${ }^{22} \mathrm{~A}$ mathematical simulation, in Italian scenario, has predicted that the restrictive social-distancing measures required to be combined with widespread testing and contact tracing, to end the ongoing COVID-19 pandemic. ${ }^{23}$ Another projection has depicted that if the community isolation measure succeeds to achieve $50 \%$ or more quarantine by test and trace procedure, the COVID-19 cases, hospitalizations, ICU requirements and deaths would to be declined by almost $90 \% .{ }^{24}$ There are different laboratory methods, used to test positive case of COVID-19. Nucleic acid amplification test (RT-PCR) from nasopharyngeal swab, oropharyngeal swab, sputum, bronchoalveolar lavage fluid measures current infection with SARS-CoV-2. ${ }^{23}$ Antibody (IgM/IgG) detection with serological sample evaluates recent exposure or previous infection of SARS-CoV-2, and facilitates contact tracing and surveillance. ${ }^{23}$ Antigen test, a low cost rapid test is used in emergency for faster detection of virus. ${ }^{25}$ South Korea did not employ lockdown, but was successful to turn the curve of infection and mortality rate down by extensive application of test, trace and isolation measures. ${ }^{26}$ Germany's response to outbreak by mass testing and effective lockdown restrictions helped the country to keep the death rate far lower, compared to other European countries. ${ }^{27}$ China controlled the second surge of infection, promptly by undertaking thorough mass testing in Wuhan. ${ }^{28}$ Also, many worst-hit countries have managed to decline daily new cases and deaths by extensive mass testing and quarantine (Figure 1). ${ }^{14}$ The highest rank of United States in number of infections was corroborated with the insufficient test rate $(2,64,000$ per day), about double or triple times below the requirement. ${ }^{29}$ On the other hand, Brazil had been performing worse in disease management, for its anti-lockdown strategy and low testing capacity (only 6,700 per day, in place of 40,000 per day, as required). ${ }^{30,31}$ Rising the peak of infection in Peru was criticised as the public failure to respect quarantine recommendations. ${ }^{32}$ The slow and steady rise in cases and deaths in India, was claimed to be due to ease the lockdown, movement of migratory workers and lowest testing rate. ${ }^{33,34}$

\section{Disease Management and Future Direction}

The prolonged stringent lockdown has negative effect on the economy of a country, related to loss of job, scarcity of food, ill mental health, social unrest etc. These are the reasons that a number of countries have started lifting lockdown to restore the economy of the country. ${ }^{15}$ But lifting of lockdown is another threat globally, having a chance of second wave of infection due to underdeveloped population immunity. Hypothetically, second surge of infection following lockdown, achieves higher peak than that of the no-action state. China encountered clusters of cases at Wuhan and Shulan cities, after lifting of strict lockdown. ${ }^{35}$ The infection of COVID-19 was reported rising in Germany, just days after the country eased its lockdown restrictions and the reproduction number has geared above 1.27. Hence, it is a challenge for the disease management to prevent transmission of virus, amid resumption of work. This situation demands for efficient forecast of infection and preparation for effective intervention measures as well as widespread mass testing and isolation, against spread of infection. There are different predictions for postlockdown measures, in the scenario of different countries. Based on the findings of wide variety of reproductive numbers ( $R$ values) at the regional level and considering the differences in local factors, a model has advocated for region-based social behavioural policies and effective testing after unlocking, instead of 'one size fits all. ${ }^{36,37} \mathrm{~A}$ phase- and epidemic region-adjusted mathematical model was effectively used to predict the number of cases of infection in Wuhan, Hubei Province and regions outside Hubei Province in China and helped the country for planned work resumption under stringent prevention and control. ${ }^{38}$ Another mathematical prediction, estimating the impact of lockdown on contact rate and reproductive number $(R e)$ in France, has recommended for keeping a low value of reproductive number to avoid an uncontrolled second wave of infection, even though, first epidemic wave has been mitigated by the lockdown. ${ }^{39}$ A lockdown model predicting impact of 21 days in some states of India has projected that the reduction in cases and deaths has occurred more steadily in the region, having higher percentage of symptomatic infected persons, suggesting for the extensive lockdown only in the regions with symptomatic patients, and relaxation of the same to the other places for some times. ${ }^{40}$ The scientists in Britain has proposed for the strategy of staggered lockdown period for another two years (unto 2022), indicating the 30 day work, followed by 50 days lockdown to break the chain of infection. ${ }^{30}$ In an attempt to calculate basic and time-varying effective reproductive number in different European, North American and Asian countries, a model has proposed for the evidence-based implementation of prompt control policies, even at late 
stage of infection, and taking advantage of time-window, through determined public health intervention to reduce rate of transmission, particularly in developing countries. ${ }^{41}$ from different parts of the globe are trying to develop effective vaccines to fight the COVID-19 pandemic. There are 10 candidate vaccines (DNA, RNA, protein-based, and

Table I.List of repurposed drugs and vaccines under clinical trial against SARS-CoV-2

\begin{tabular}{|c|c|c|c|}
\hline \multicolumn{2}{|r|}{ Drugs } & \multicolumn{2}{|l|}{ Vaccines } \\
\hline $\begin{array}{l}\text { Product type and } \\
\text { candidate }\end{array}$ & Description & Type of candidate vaccine & $\begin{array}{l}\text { Stages of clinical } \\
\text { evaluation }\end{array}$ \\
\hline GS-7534/ Remdisivir & Nucleotide inhibitor & $\begin{array}{l}\text { Non-replicating viral vector } \\
\text { ChAdOx1-S vaccine }\end{array}$ & Phase $2 b / 3$ \\
\hline Corticosteroid & Steroid hormones & $\begin{array}{l}\text { Lipid nanoparticle-encapsulated } \\
\text { mRNA vaccines }\end{array}$ & Phase 2 \\
\hline Chloroquinine & Antimalarial agent & $\begin{array}{l}\text { SARS CoV-2 glycoprotein } \\
\text { nanoparticle vaccine }\end{array}$ & Phase $1 / 2$ \\
\hline Darunavir & Antiretroviral protease inhibitor & $\begin{array}{l}\text { DNA plasmid vaccine with } \\
\text { electroporation }\end{array}$ & Phase 1 \\
\hline Ruxolitinib & $\begin{array}{c}\text { Myelofibrosis and } \\
\text { polycythaemia treatment }\end{array}$ & Adenovirus Type 5 CanSino & Phase 2 \\
\hline INF- $a 2 b$ & $\begin{array}{l}\text { Type I interferon made by } \\
\text { leukocytes during viral infection }\end{array}$ & 3 LNP-mRNAs & Phase $1 / 2$ \\
\hline Baloxavir marboxil & Antiviral endonuclease inhibitor & $\begin{array}{l}\text { Inactivated vaccines } \\
\text { (ChiCTR2000031809) }\end{array}$ & Phase $1 / 2$ \\
\hline Favipiravir & Viral RNA polymerase inhibitor & $\begin{array}{l}\text { Inactivated vaccines } \\
\text { (ChiCTR2000032459) }\end{array}$ & Phase $1 / 2$ \\
\hline Umifenovir & $\begin{array}{c}\text { Russian-made small indole- } \\
\text { derivative molecule }\end{array}$ & $\begin{array}{c}\text { Inactivated+alum vaccines } \\
\text { (NCT04383574, NCT04352608) }\end{array}$ & Phase $1 / 2$ \\
\hline Novaferon & $\begin{array}{l}\text { Recombinant protein produced } \\
\text { by DNA-shuffling of IFN- } a\end{array}$ & Inactivated vaccines (NCT04412538) & Phase 1 \\
\hline Ritonavir plus Lopinavir & Protease inhibitor & & \\
\hline $\begin{array}{l}\text { Emtricitabine plus } \\
\text { tenofovir }\end{array}$ & $\begin{array}{l}\text { Non-nucleoside reverse } \\
\text { transcriptase inhibitor }\end{array}$ & & \\
\hline
\end{tabular}

\section{Current Therapeutics}

Currently, there is no evidence of effective drugs for the treatment of COVID-19 symptoms. The therapeutic approach for COVID-19 has been relying, mostly, on drug repurposing. Some of the drugs are presently under clinical trial against SARS-CoV-2 (Table 1). ${ }^{42}$ To date, two drugs have got approval to treat COVID-19 that are Avigan (favipiravir) in China, Italy and Russia, and Veklury (Remdisivir) in Japan. ${ }^{43,44}$ However, there are reports of successful use of some other combination of drugs in the treatment of patients in some countries that require elaborate evaluation. These drugs include Doxycycline plus Ivermectin (antibiotic and antiprotozoal), aspirin plus warfarin (blood thinner), Rintatolimod plus IFN Alpha-2b (double stranded Ribonucleic Acid (RNA) designed to mimic viral infection and chemokine), Favipiravir plus Umifenovir (antiviral), and hydroxychloroquine (in low dose - 50-100 mg daily) plus alpha-2b (intranasal interferon spray). ${ }^{45-49}$ Moreover, the companies and institutions inactivated) in different phases of clinical evaluation (Table 1) and 126 vaccines in preclinical trial, targeting $S$ protein or whole virion..$^{50}$

\section{Conclusion}

SARS-CoV-2 is the etiological agent for COVID-19, the ongoing worldwide pandemic of severe acute respiratory syndrome. Serological studies have shown that a relatively low proportion of the population has acquired antibody against COVID-19. ${ }^{15}$ The development of herd immunity or the availability of effective vaccines for long term protection is a far cry. Nevertheless, there is no useful drug to treat the COVID-19 symptoms. In this situation, the disease management is the only way to control the disease. Lockdown was adopted by different countries as the primary measure to raise social distancing to minimize transmission of virus. The 'test, trace, track and isolation', the other measure, was recommended during lockdown, for extensive mass testing 
to trace the infected persons (especially asymptomatic or mild symptomatic) and quarantined them. Social distancing and widespread mass testing measures, together, helped many worst-hit countries to lower down the number of infection and death than the maximum upsurge. On the other hand, few countries have emerged as new hotspot of disease with accelerated daily new cases and death, owing to insufficient testing and isolation measure than requirement. However, several countries have been lifting lockdown, in phases to handle the economic stress. The lifting lockdown is a threat, having chance of second wave of infection. In present scenario, the major challenge is the prevention of spread of infection, amid resumption of work. Thereby, the disease management would require the efficient forecast of infected cases and risk of transmission of virus in a region-based manner (in contrary to 'one size fits all') and prediction of effective intervention strategy as well as extensive mass testing and isolation to prevent the spread of the virus, in future. However, the researchers and scientists of global community have been working diligently to identify drugs and develop suitable vaccines to combat the disease.

\section{Acknowledgement}

The authors acknowledge the support of Department of Zoology, S. A. Jaipuria College, Kolkata, India and Centre for Bioinformatics, Pondicherry University, Pondicherry, India for providing the infrastructural facilities.

\section{Conflict of Interest: None}

\section{References}

1. Lu R, Zhao X, Li J et al. Genomic characterisation and epidemiology of 2019 novel coronavirus: implications for virus origins and receptor binding. Lancet 2020; 395: 565-574.

2. McBride R, van Zyl M, Fielding BC. The coronavirus nucleocapsid is a multifunctional protein. Viruses 2014; 6: 2991-3018.

3. Lu H, Stratton CW, Tang YW. Outbreak of pneumonia of unknown etiology in Wuhan, China: The mystery and the miracle. J Med Virol 2020; 92: 401-402.

4. Liu Y, Gayle AA, Wilder-Smith A et al. The reproductive number of COVID-19 is higher compared to SARS coronavirus. J Travel Med 2020; 27(2): taaa021.

5. Modes of transmission of virus causing COVID-19: implications for IPC precaution recommendations. Available from: https://www.who.int/news-room/ commentaries/detail/modes-of-transmission-of-viruscausing-COVID-19-implications-for-ipc-precautionrecommendations. Accessed on: 4 Jun 2020.

6. van Doremalen N, Bushmaker T, Morris DH et al. Aerosol and surface stability of SARS-CoV-2 as compared with SARS-CoV-1. N Engl J Med 2020; 382: 1564-7.

7. Hoffmann M, Kleine-Weber H, Schroeder S et al. SARS-
CoV-2 cell entry depends on ACE2 and TMPRSS2 and is blocked by a clinically proven protease inhibitor. Cell 2020; 181: 271-80.e8.

8. Sungnak $W$, Huang $N$, Bécavin C et al. SARS-CoV-2 entry factors are highly expressed in nasal epithelial cells together with innate immune genes. Nat Med 2020; 26: 681-687.

9. Coronavirus. Available from: https://www.who.int/ health-topics/coronavirus. Accessed on: 4 June 2020.

10. Rose DU, Piersigilli F, Ronchetti MP et al. Novel Coronavirus disease (COVID-19) in new-borns and infants: what we know so far. Italian Journal of Paediatrics 2020; 46: 56.

11. Statement - Older people are at highest risk from COVID-19, but all must act to prevent community spread. 2020 Available from: http://www.euro.who. int/en/health-topics/health-emergencies/coronavirusCOVID-19/statements/statement-older-people-areat-highest-risk-from-COVID-19,-but-all-must-act-toprevent-community-spread. Published on: Apr 2, 2020. Accessed on: 4 June 2020.

12. Furukawa NW, Brooks JT, Sobel J. Evidence Supporting Transmission of Severe Acute Respiratory Syndrome Coronavirus 2 While Presymptomatic or Asymptomatic. Emerging Infectious Diseases 2020. Available from: https://wwwnc.cdc.gov/eid/article/26/7/20-1595_ article. Accessed on: 4 June 2020.

13. Khanna R, Cicinelli M, Gilbert S et al. COVID-19 pandemic: Lessons learned and future directions. Indian Journal of Ophthalmology 2020; 68(5): 703-710.

14. Coronavirus Update (Live): $7,477,428$ Cases and 419,373 Deaths from COVID-19 Virus Pandemic - Worldometer. Available from: https://www.worldometers.info/ coronavirus/. Accessible on: Jun 15, 2020.

15. WHO Director-General's opening remarks at the media briefing on COVID-19 - 11 May 2020. Available from: https://www.who.int/dg/speeches/detail/who-directorgeneral-s-opening-remarks-at-the-media-briefing-onCOVID-19---11-may-2020. Accessible on: 4 June, 2020.

16. Li B-Z, Cao N-W, Zhou H-Y et al. Strong policies control the spread of COVID-19 in China. J Med Virol 2020.

17. Pan A, Liu L, Wang C et al. Association of public health interventions with the epidemiology of the COVID-19 Outbreak in Wuhan, China. JAMA 2020; 323(19): 1-9.

18. PTI. WHO lauds India's "tough and timely" actions against corona virus. The Hindu, 2020.

19. Ghosal S, Bhattacharyya R, Majumder M. Impact of complete lockdown on total infection and death rates: A hierarchical cluster analysis. Diabetes MetabSyndr 2020; 14: 707-711.

20. Peng Z, Song $W$, Ding Z et al. Linking key intervention timings to rapid declining effective reproduction number to quantify lessons against COVID-19. Front Med., 2020.

21. Sweden to ramp up coronavirus testing. Available from: 
https://medicalxpress.com/news/2020-05-swedenramp-coronavirus.html. Accessible on: 4 June, 2020.

22. Patel R, Babady E, Theel ES et al. Report from the American Society for Microbiology COVID-19 International Summit, 23 March 2020: value of diagnostic testing for SARS-CoV-2/COVID-19. MBio 2020; 11(2): e00722-20.

23. Giordano G, Blanchini F, Bruno R et al. Modelling the COVID-19 epidemic and implementation of populationwide interventions in Italy. Nat Med 2020; 26: 855-860.

24. Chatterjee K, Chatterjee K, Kumar A et al. Healthcare impact of COVID-19 epidemic in India: A stochastic mathematical model. Armed Forces Med J India 2020; 76(2): 147-155.

25. Kim S. FDA gives emergency authorization for new antigen test to help detect coronavirus quicker and cheaper. 2020.

26. Normile D. Coronavirus cases have dropped sharply in South Korea. What's the secret to its success? Science, 2020.

27. BBC News. Infection rate rises in Germany as lockdown eases. BBC News, 2020.

28. Reality Check team. Coronavirus: China's plan to test everyone in Wuhan. BBC News, 2020.

29. Meyer R. There's One Big Reason the U.S. Economy Can't Reopen. The Atlantic, 2020.

30. Chaturvedi A. 50-day lockdown, relaxation for 30 days: British scientists suggest new model to beat COVID-19. Hindustan Times, 2020.

31. AP. Brazil becoming coronavirus hot spot as testing falters. The Hindu, 2020.

32. Al Jazeera News. Peru extends nationwide lockdown until end of June, 2020.

33. BBC News. India records highest spike in COVID-19 cases. BBC News, 2020.

34. HT Correspondent. One-third of migrant workers could be infected with COVID-19: Centre tells SC. Hindustan Times, 2020.

35. $A B C$ News. Wuhan records first new COVID cases since lockdown was lifted. ABC News, 2020.

36. Stedman M, Davies M, Lunt M et al. A phased approach to unlocking during the COVID-19 pandemic-Lessons from trend analysis. Int J Clin Pract 2020; 00: e13528.

37. Stedman $M$, Lunt $M$, Davies $M$ et al. COVID-19: Modelling Local Transmission and Morbidity effects to provide an estimate of overall Relative Healthcare Resource Impact by General Practice Granularity. Available from: https://www.medrxiv.org/ content/10.1101/2020.03.20.20039024v1. Accessible on: 4 June, 2020.

38. Chang $\mathrm{R}$, Wang $\mathrm{H}$, Zhang $\mathrm{S}$ et al. Phase- and epidemic region-adjusted estimation of the number of coronavirus disease 2019 cases in China. Front Med 2020; 14: 199209.
39. Roques L, Klein EK, Papaïx J et al. Impact of lockdown on the epidemic dynamics of COVID-19 in France. Frontiers in Medicine, 2020.

40. Sardar T, Nadim SS, Chattopadhyay J. Assessment of 21 days lockdown effect in some states and overall India: A predictive mathematical study on COVID-19 outbreak. Chaos Solitons Fractals 2020; 139: 110078.

41. Xu C, Dong Y, Yu X et al. Estimation of reproduction numbers of COVID-19 in typical countries and epidemic trends under different prevention and control scenarios. Front Med 2020, 1-10.

42. WHO. Landscape analysis of therapeutics as 21st March 2020. Available from: https://www.who.int/blueprint/ priority-diseases/key-action/Table_of_therapeutics_ Appendix_17022020.pdf.

43. Desk W. Russia to use antiviral drug Favipiravir against COVID-19. 2020. Available from: https://www.theweek. in/news/world/2020/04/07/russia-to-use-antiviraldrug-favipiravir-against-COVID-19.html.

44. Gilead Announces Approval of Veklury ${ }^{\circledR}$ (Remdisivir) in Japan for patients with severe COVID-19. Available from: https://www.gilead.com/news-and-press/press-room/ press-releases/2020/5/gilead-announces-approval-ofveklury-remdesivir-in-japan-for-patients-with-severeCOVID19.

45. Found effective drug combination to cure COVID-19 patients: Bangladeshi doctors. 2020. Available from: https://www.hindustantimes.com/indianews/found-effective-drug-combination-to-cureCOVID-19-patients-bangladeshi-doctors/storyK8zOYQD43b2KbptPQAwLdO.html.

46. Blood thinners may improve survival among hospitalized COVID-19 patients: Research could change standard of care protocols to prevent clotting associated with coronavirus. 2020. Available from: https://www. sciencedaily.com/releases/2020/05/200507194907. html.

47. Peter K. Blood thinners as a treatment for COVID-19? What the science says and what it means for you. Available from: https://medicalxpress.com/news/202005-blood-thinners-treatment-COVID-science.html.

48. Rintatolimod and IFN Alpha-2b for the treatment of mild or moderate COVID-19 infection in cancer patients. Available: from: https://clinicaltrials.gov/ct2/show/ NCT04379518.

49. Use of hydroxychloroquine and interferon alpha-2b for the prophylaxis of COVID-19. Med Hypotheses 2020; 144: 109802.

50. WHO. Draft landscape of COVID-19 candidate vaccines. Available: from: https://www.who.int/who-documentsdetail/draft-landscape-of-covid-19-candidate-vaccines. 